\title{
O LEGADO DE KOWARICK: CONVITE AO COMPROMISSO COM A PESQUISA URBANA
}

\author{
Vivian Prado Pereira ${ }^{1}$
}

\begin{abstract}
Resumo:
O objetivo deste trabalho consiste em apontar as principais contribuições do autor para o campo da sociologia urbana brasileira. Para isso buscaremos resgatar a gênese da construção do urbano enquanto questão pelas ciências sociais brasileiras e o papel desempenhado por Kowarick tanto na ocasião da emergência do debate, quanto no desenrolar da construção do tema com o passar dos anos, refletindo sobre o legado por ele deixado. Cientes de que o reconhecimento por sua relevância analítica e seu pioneirismo se dá, em grande medida, por seu engajamento com a empiria e pela busca por interpretações consistentes acerca das características e nuances da realidade urbana brasileira, destacamos o entusiasmo do autor com o campo das pesquisas urbanas no Brasil e seu empenho para promover uma construção teórica coletiva. Resgatamos o convite aberto feito aos demais pesquisadores do urbano para firmar um compromisso de trabalho com a materialidade e com a construção de uma sociologia urbana autêntica e ajustada à experiência brasileira.
\end{abstract}

Palavras-chave: Sociologia urbana. Metodologia de pesquisa. Lúcio Kowarick.

\section{KOWARICK'S LEGACY: CALL FOR COMMITMENT TO URBAN RESEARCH}

\begin{abstract}
:
The aim of this work is to point out the main contributions of the author to the field of Brazilian urban sociology. To this end, we will seek to rescue the genesis of the construction of the urban as a question for Brazilian social sciences and the role played by Kowarick both at the time of the emergence of the debate and in the development of the theme over the years, reflecting on the legacy he left. Aware that recognition for its analytical relevance and pioneering spirit is largely due to its engagement with empiricism and the search for consistent interpretations about the characteristics and nuances of the Brazilian urban reality, we highlight author's enthusiasm for the field of urban research in Brazil and his efforts to promote a collective theoretical construction. We rescued the open invitation made to the other urban researchers to sign a commitment to work with materiality and with the construction of an authentic urban sociology, adjusted to Brazilian experience.
\end{abstract}

Keywords: Urban Sociology. Research Methodology. Lúcio Kowarick.

\footnotetext{
${ }^{1}$ Doutoranda em Ciências Sociais pela Universidade Federal de Juiz de Fora (PPGCSO/UFJF), mestre em Planejamento Urbano e Regional (IPPUR/UFRJ). E-mail: vivian.vpp@gmail.com.
} 


\section{Introdução}

Quando pensamos na trajetória dos estudos urbanos realizados no Brasil, o nome de Lúcio Kowarick aparece como um dos primeiros que despontam. O reconhecimento de sua relevância e pioneirismo analíticos se dá, em grande medida, por seu compromisso com a empiria e por sua busca incansável em desvelar as características e nuances da realidade urbana brasileira. O objetivo deste trabalho consiste em apontar as principais contribuições do autor para o campo da sociologia urbana brasileira. Para isso, buscaremos resgatar, em linhas gerais, a gênese da construção do urbano enquanto questão pelas ciências sociais brasileiras e o papel desempenhado por Kowarick tanto na ocasião da emergência do debate, quanto no desenrolar da construção do tema, com o passar do tempo, ao longo dos anos, refletindo sobre o legado por ele deixado.

Para alcançar elucidar os princípios que norteiam as escolhas intelectuais do autor, parece pertinente recuperar sua inserção no campo teórico dos estudos urbanos e indicar o pensamento de outras autoras e autores que, a nosso ver, confluem na construção e crítica do pensamento urbano no Brasil. A reflexão que se propõem passa, portanto, pela identificação e restauração da sociologia urbana deliberadamente marcada por um compromisso com a experiência brasileira.

\section{Gênese da sociologia urbana no Brasil}

O surgimento da "cidade enquanto questão" nas ciências sociais brasileiras ocorre no final dos anos 1960 e, em grande medida, acompanhando o debate promovido no mesmo período pela produção de neomarxistas franceses, com ênfase nas figuras de Castells e Lefebvre. Para esses sociólogos franceses, os fenômenos urbanos não poderiam ser vistos como autônomos e isoladamente explicativos, mas sim como parte de uma estrutura mais ampla, em que convergiam exigências econômicas, arranjos políticos e atores sociais.

As sociólogas e sociólogos brasileiros das décadas de 1960 e 1970 fizeram do tema da pobreza e da marginalidade seu foco de atenção. A partir de pesquisas pioneiras, como as de Machado da Silva (1971), Oliveira (1972) e Kowarick (1979), tornou-se possível demonstrar que a reprodução do padrão de desigualdade se tratava menos de um problema de integração social e mais de uma questão estrutural. "Estabelecia-se, então, uma ruptura com as concepções anteriores sobre migração e marginalidade, e trazia-se à tona o papel desempenhado por formas não capitalistas de produção na acumulação do capital" (VALLADARES; FREIREMEDEIROS, 2002, p. 66).

Kowarick e outros estudiosos brasileiros vão, nesse primeiro momento, buscar uma análise do urbano articulada com as condições de vida da classe trabalhadora e examinar a funcionalidade do então modelo de expansão urbana para o desenvolvimento capitalista das cidades. Francisco de Oliveira, em seu ensaio "Crítica à razão dualista", de 1972, explicitou a articulação entre o "arcaico" e o "moderno" no processo de crescimento das cidades brasileiras a partir da expansão do capitalismo industrial no pós-anos 1930. O autor vai apontar que a forma aparentemente anárquica do crescimento urbano responde, em verdade, aos imperativos da acumulação capitalista. De modo que práticas supostamente de sobrevivência ou desarticuladas dos propósitos da acumulação serviam ao barateamento da reprodução da força 
de trabalho, possibilitando o desenvolvimento do modelo de expansão capitalista, que tinha uma das bases de seu dinamismo na intensa exploração dessa força de trabalho (OLIVEIRA, 2003).

Oliveira contribuiu, assim, para a gênese de uma sociologia urbana de cunho estruturalista e que destacava a dimensão política da urbanização. Buscando compreender, principalmente, os modos como o capital subjugava a força de trabalho e como a lógica da expansão urbana negava aos cidadãos o acesso aos bens de consumo coletivos, proliferavam estudos que apostariam em um conjunto cruzado de temas, entre os quais classes e conflito social, contradições urbanas e Estado, exploração e espoliação urbana, autoconstrução e periferização urbana etc. (TELLES, 2010).

A noção de periferia ganhava força analítica no campo das ciências sociais no Brasil por meio de estudos que enfatizavam as condições de vida da classe trabalhadora nas metrópoles. O espaço urbano privilegiado seria, em São Paulo, o da periferia, tendo a autoconstrução como elemento-chave de análise, principalmente com base em trabalhos, como os de Lúcio Kowarick (1979), Ermínia Maricato (1979) e Raquel Rolnick e Nabil Bonduki (1979). Enquanto isso, no Rio de Janeiro, dava-se ênfase às dinâmicas que culminavam na proliferação de favelas, com trabalhos como os de Machado da Silva (1971), Perlman (1977) e Leeds e Leeds (1978).

No decorrer da década de 1980, a contribuição da sociologia para os estudos urbanos no Brasil aparece muito vinculada à conjuntura sócio-política, marcada pelos efeitos da abertura democrática, da crise econômica na produção e por um projeto de modernidade. Ainda apresentando um número significativo de trabalhos com as temáticas de habitação e pobreza, a grande novidade desse período será o destaque aos movimentos sociais urbanos. As lutas por acesso à cidadania assumem um sentido mais amplo, de modo que, se antes as mobilizações sociais eram usualmente encaradas como respostas à crise econômica, a partir desse momento surge a necessidade de entender os movimentos sociais também em suas dimensões cultural e política. A ênfase, até então dada à estrutura nos estudos urbanos, passa a ser substituída por uma abordagem sociocultural. (VALLADARES; FREIRE-MEDEIROS, 2002).

Desponta o debate sobre o papel da democracia na redução das desigualdades e a pobreza urbana passa a ser analisada por diferentes frentes, como gênero, mercado de trabalho, infância, população de rua e violência. Já no fim da década, na esteira da promulgação da Constituição em 1988, a sociedade e a comunidade científica brasileira mobilizavam-se em torno de temas como a universalização dos direitos civis, políticos e sociais dos cidadãos, a descentralização político-administrativa e a reforma urbana. A descentralização veio, desse modo, se tornando uma questão fundamental para a pesquisa sociológica urbana, acompanhada das temáticas de governabilidade, governança, gestão urbana e políticas públicas (VALLADARES; FREIRE-MEDEIROS, 2002).

Aproximando-se do final dos anos 1990, observa-se um esforço reflexivo da sociologia urbana em torno de temas como meio ambiente e desenvolvimento sustentável, alinhados com a perspectiva da melhoria da qualidade de vida nas cidades e da gestão urbana. Os anos 2000 iniciam-se com o surgimento de trabalhos sobre o tema da globalização, apontando para a hipótese de que uma nova ordem urbano-espacial estaria emergindo como manifestação da "nova ordem mundial" e questionando os efeitos visíveis da globalização na estrutura interna das cidades brasileiras (VALLADARES; FREIRE-MEDEIROS, 2002). 


\section{A trajetória intelectual de Lúcio Kowarick}

Telles (2010), ao buscar compreender as linhas de força que conduziram os caminhos das pesquisas urbanas no Brasil desde seu o surgimento até os dias de hoje, enfatiza que a gênese da fundamentação da "cidade enquanto questão" esteve fortemente assentada na conjuntura política e econômica vivenciada no país a partir dos anos 1960. Aponta que os macroprocessos históricos e estruturais que definiam os rumos e futuros possíveis da sociedade brasileira - e de toda a América Latina - se realizavam nas cidades (que cresciam vertiginosamente) e fomentaram a construção de um debate teórico-material sobre o urbano que era definido sob a perspectiva do progresso, da mudança social e do desenvolvimento.

Nas cidades, todo esse processo ganhava forma, estava corporificado nos seus espaços, pulsava na nova estrutura de classes que aí se materializava e explodia na pobreza urbana, na massa crescente de trabalhadores pobres que se virava por sua própria conta e risco nas periferias que então se expandiam e nas mil faces do problema urbano (...) (TELLES, 2010, p. 59).

Pesquisas sobre processos de periferização urbana, moradia popular, desigualdades e relações de classe proliferavam nos debates promovidos pela academia, que tinham como pano de fundo as "contradições urbanas" promovidas pelo capitalismo moderno.

Interessado em analisar os processos que se desencadeavam na cidade de São Paulo e os caminhos que a levavam a se constituir no que denomina metrópole do subdesenvolvimento industrializado, Kowarick publica em 1979 o livro A espoliação urbana. Associando elementos como o pressionamento dos salários, a facilidade de substituição da mão de obra, o afastamento dos trabalhadores para as fronteiras urbanas e a autoconstrução de moradias, o autor cunha o conceito de espoliação urbana. Esse processo se realizaria pela somatória de extorsões às quais estão submetidos os trabalhadores urbanos: para além da exploração vivenciada na venda da força de trabalho, a periferia como fórmula de reprodução nas cidades engendrou formas espoliativas que se dão ao nível da própria condição urbana de existência a que foi submetida essa classe trabalhadora.

A ausência e/ou precariedade de infraestrutura e serviços de consumo coletivo associadas ao fato de os salários não incorporarem, entre outros itens, os custos com moradia, lazer e saúde - expõem os trabalhadores a múltiplas situações de espoliação, tendo em vista que precisam, por exemplo, recorrer a práticas de mutirão e autoconstrução para ter acesso à moradia, despender horas nos tortuosos e longos trajetos entre casa e trabalho, em transportes públicos de péssima qualidade, e habitar espaços da cidade que não oferecem estruturas básicas que assegurem qualidade de vida, como redes de distribuição de água tratada e de coleta de esgotos.

Inquestionavelmente arrojado e pertinente já nessa primeira versão, o conceito de espoliação urbana será revisitado por Kowarick vinte anos mais tarde, no livro Escritos Urbanos (2000). O autor reconhece que essa construção inicial traz um esforço teórico em relação à relativa autonomia da assim chamada questão urbana. Mas ainda está conectado e é resultante da dinâmica econômica. Na trajetória intelectual apresentada no livro, o autor retoma o tema das lutas urbanas, agora motivado, principalmente, por uma crítica ao determinismo estrutural que sugere uma relação direta entre as contradições urbanas e as transformações 
sociais. Busca destacar que as condições materiais objetivas não são suficientes para tomar para si o protagonismo da ação coletiva.

Em outros termos, em vez de atrelar a análise das condições urbanas de existência às vicissitudes da expansão capitalista e deduzir as lutas sociais da precariedade que as caracterizam, parece analiticamente mais promissor indagar o significado que essa materialidade tem para os múltiplos atores que se enfrentam na arena social. (KOWARICK, 2000, p. 106).

Essa mudança de coloração teórica apresentada pelo autor reside em destacar que a espoliação urbana não se configura apenas como outra faceta do trabalhador pauperizado, passando a enfatizar a problemática da subjetividade social. Ela é resultado não só do processo de acumulação de capital, mas também da dinâmica das lutas protagonizadas pelos trabalhadores e de seu êxito em pressionar o Estado e dele obter os meios básicos de sobrevivência nas cidades. Para Kowarick, a noção de espoliação extrapola a ideia de que existe a necessidade de acesso à moradia e aos serviços de consumos coletivos (como água encanada, rede de esgoto, transporte público, instituições de saúde e educação etc.). Trata-se de uma construção histórica que advém das lutas sociais, de uma percepção coletiva que considera que existe legitimidade nas reivindicações por acesso aos bens comuns julgados socialmente necessários e cuja negação constitui uma injustiça.

É preciso também pontuar o mérito do autor em buscar trazer em seus escritos análises e referências acerca da precariedade das condições materiais urbanas em outras metrópoles latino-americanas, com ênfase no desenrolar dos movimentos sociais e lutas urbanas presentes nos diferentes países. Deixando patente que os países latino-americanos têm seus processos de acumulação fincados no empobrecimento real da maioria dos assalariados e que a luta contra a extorsão promovida pela espoliação urbana está, sob diferentes modalidades e intensidades, vigente nas cidades.

Naturalmente, as lutas sociais não podem ser deduzidas das determinações macroestruturais que constrangem os moradores das metrópoles latino-americanas. Isso porque, a despeito de uma situação partilhada de vulnerabilidade e exclusão socioeconômica, os conflitos se manifestam de diferentes maneiras e as experiências de luta apresentam trajetórias singulares. Kowarick entende as condições estruturais, a pauperização e a espoliação como matérias-primas que potencialmente alimentam os conflitos sociais, de modo que entre e as contradições urbanas e as lutas que se sucedem há um processo de produção de experiências.

Fica evidente a preocupação científica de Kowarick com o reconhecimento dos sentidos que assumem a vulnerabilidade e a precariedade urbanas entre os sujeitos que transitam nos limites da pobreza, marcados pelo desemprego, pelo trabalho precário e pela ausência de garantias sociais. Em seu livro Viver em risco: sobre a vulnerabilidade socioeconômica e civil, publicado em 2009, busca, a partir de um trabalho histórico, sociológico e etnográfico, debater sobre a diversidade da pobreza urbana, e lança uma questão central que, como afirma Telles no prefácio, figura como um plano de referência conceitual e político de suas obras: "a cidade como espaço de lutas e o conflito como dimensão estruturante das dinâmicas urbanas e suas evoluções no tempo" (p. 14).

O tema da vulnerabilidade e do que o autor vai chamar de subcidadania pública aparece em seus trabalhos acompanhando o debate sobre o sentido político que perpassa as categorias explicativas mobilizadas no campo intelectual. A chave analítica que Kowarick busca elaborar 
parte do reconhecimento do descompasso entre a consolidação democrática e o bloqueio ao acesso à universalização dos direitos básicos, civis e sociais, e da consideração do modo como os diferentes atores vivenciam e reagem à vulnerabilidade e à precariedade urbanas. Entretanto, o raciocínio do autor passa à margem do pragmatismo gestionário, as questões que propõe não se enquadram no campo gestão das urgências, ou na busca por soluções imediatas (KOWARICK, 2009).

À noção de subcidadão público ele contrapõe a de cidadão privado. No espaço público impera a subcidadania, que se traduz na banalidade da violência cotidiana, no desamparo, em experiências de desrespeito, medo e humilhação. Em face das dificuldades para manutenção e conquista dos direitos sociais, da inexistência de políticas de proteção, aflora o cidadão privado, que encarna a realização de um projeto individual de existência. Será no âmbito da vida privada, da sociabilidade primária da família e amigos que se engendrará o refúgio: "estruturada em torno da casa e da vizinhança, desses pedaços reconhecidos como solidários, de proteção e ajuda mútua, muitos organizam formas defensivas para enfrentar as múltiplas violências que marcam o dia a dia na Metrópole e elaboram projetos para usufruir de suas oportunidades" (KOWARICK, 2000, p. 115).

Fica posto que o interesse de Kowarick está, primordialmente, em compreender em que medida as experiências de desrespeito e a subcidadania passam a se constituir como matériaprima de lutas coletivas. Quais os caminhos percorridos pelos grupos precarizados desde a percepção da indignidade e injustiça às quais estão submetidos até a elaboração de ações coletivas de reivindicação e resistência? Kowarick recorre à construção Thompsiana de experiência para refletir sobre insubordinação, resistências e mudanças sociais.

O último texto de Kowarick, Sobre a construção de um instrumento de análise: a espoliação urbana, publicado em 2020, traz uma reflexão sobre os caminhos teóricos e metodológicos percorridos ao longo de sua vida como pesquisador. Substancial e inspirador, o autor relembra o início de sua carreira de pesquisas com periferias urbanas. Kowarick revisita um estudo sobre favelas realizado em parceria com Ruth Cardoso, no ano de 1973, do qual parte dos resultados foi publicada como capítulo (7- Os cidadãos da Marginal) em seu livro A espoliação urbana, em 1979. Os trechos rememorados contêm, a nosso ver, elementos e questionamentos fundantes do modo como o autor buscou conduzir seus trabalhos no decorrer da vida acadêmica. Nesse fragmento, os pesquisadores fazem uma reflexão sobre as percepções de vida dos personagens da pesquisa; não se trata de um ensaio apenas materialista histórico, mas sim de um exemplar de sensibilidade e ponderação sobre a realidade que se interpõe e os caminhos possíveis:

O desespero do goleiro Cláudio e a prostração do camponês Honório têm algo em comum: de certo modo, ambos vivem o fim de uma festa que não houve. São trabalhadores que não têm mais a única coisa que tiveram no decorrer de suas vidas: a força de trabalho para vender. Criaram riquezas, plantaram, construíram, defenderam pênaltis. Mas nada disto lhes pertence. [...] Para eles, não há mais a criação de um futuro. E também não há revolta. Inexiste o sentimento de união, de percepção do semelhante: a tragédia não se adiciona: [...] a tragédia é natural, ela é assim porque as coisas sempre foram assim. Por isso não enxergam violência das pedras que caem e soterram os barracos. (KOWARICK; CARVALHOSA; GRAEFF, 1979, p. 182).

Os mais jovens, João e Otaviano, 
E um não reconhece o outro na semelhança dos contrastes. Nem reconhecem os outros que a eles se opõem [...]. Impera o imediatismo das soluções que permanecem no presente, jogando um tempo do futuro. Talvez porque ambos sintam, isso sim, que seu futuro é o presente de Claudio e Honório - força de trabalho que se esgota ao criar uma riqueza que não e sua. (KOWARICK; CARVALHOSA; GRAEFF, 1979, p. 183).

E os autores finalizam o capítulo com a pergunta: "Ou há um outro fim e outro começo para a história das consciências soterradas?" (KOWARICK, 1979, p. 183). Parece notório reconhecer que o tema da "luta por reconhecimento" (HONNETH, 2014), da produção de experiências, da percepção da necessidade de construção de uma subjetividade compartilhada para o desenrolar das lutas sociais, figuravam no pensamento de Kowarick já no princípio de sua trajetória. A maturidade no desenvolvimento de seus argumentos teóricos desponta progressivamente em seus textos, informando, como indica o próprio ator, o caráter cumulativo, dinâmico e coletivo de suas teorias para pensar o urbano brasileiro.

\section{Reflexões epistemológicas sobre os caminhos da pesquisa urbana no Brasil}

Para Kowarick (2000), as investigações nas ciências sociais sobre a questão urbana na América Latina e no Brasil deixaram de avançar nos anos 1980, à medida que se adotavam modelos interpretativos pouco "calibrados" para compreender os processos urbanos que aqui experimentávamos. Os estudos urbanos apoiados, inicialmente, em uma perspectiva teórica francesa, de caráter macroestrutural e formulada para decifrar o capitalismo monopolista de Estado dos países do centro - ao passo que não realizaram uma renovação conceitual que permitisse uma aproximação com processos e transformações vivenciados nas nossas cidades , perderam força de análise, sendo substituídos por um viés interpretativo apoiado nas microdinâmicas da sociedade civil, na fragmentação do poder e na potência revolucionária dos atos cotidianos e parciais. Grosso modo, passamos de uma análise de estruturas sem sujeito, para uma de sujeitos sem estrutura.

Em termos muito abreviados, essa é a trajetória intelectual latino-americana da estrutura sem sujeitos. Seu inverso, ao rechaçar as explicações globalizantes e ao desatar os atores sociais de qualquer constrangimento estrutural, não pode deixar de cair numa versão que valoriza as pequenas lutas do dia a dia, caracterizada pela pluralidade dos agentes e pela diluição da própria ideia de sujeitos de transformação histórica. (KOWARICK, 2000, p. 126).

Diferentemente do paradigma genético-finalista, construído pelas abordagens estruturalistas, que atribuía aos movimentos urbanos uma espécie de vocação metafisica, acreditando que, guiados pelas contradições urbanas, promoveriam a superação do subdesenvolvimento por meio de uma "revolução urbana" virtuosa, o novo enfoque urbano pautava a mudança social pelas práticas fragmentadas dos atores. Sem dúvida, não se pode deixar de reconhecer que as ações cotidianas, práticas de ajuda mútua e estratégias de sobrevivência elaboradas e acionadas pelos sujeitos constituem processos importantes para a reprodução da vida e do espaço urbano nas periferias. Não obstante, tais práticas precisam estar referenciadas pelas condições materiais objetivas, sob o risco de reproduzirmos uma análise reducionista ou idealizada. 
Se os esquemas macroestruturais não explicam os movimentos da sociedade, pois carecem de sujeitos históricos que impulsionem suas mudanças, a visão basista que dilui os atores numa multiplicidade de cenários e agendas acaba por fazer com que eles conquistem uma liberdade que não os leva a parte alguma. (KOWARICK, 2000, p. 128).

Cortado (2018) aponta que, a partir dos anos 1990, os estudos clássicos sobre a cidade que envolviam o tríptico periferia-loteamento-autoconstrução começam a perder espaço na agenda dos estudos urbanos, tanto do lado da sociologia quanto da antropologia. Efetivamente, a periferia como lugar de pesquisa não se desfez, mas os pesquisadores passaram a se dedicar à investigação de outras temáticas urbanas. $\mathrm{O}$ foco na correlação entre a distância social e a distância geográfica, com investimento no entendimento dos processos históricos e econômicos que engendravam o movimento da urbanização foi, gradativamente, sendo substituído por uma ampla gama de estudos culturais e comportamentais que envolveu uma forte produção de etnografias urbanas no campo da antropologia.

Como já apontado anteriormente, a consistência analítica dos estudos urbanos, enquanto campo de pesquisa nascente, deu-se, em grande medida, pelo plano no qual se apoiava, que fazia da cidade um ponto de condensação de um conjunto de questões que atravessavam a experiência urbana e que se orientavam, também, por um projeto não apenas de cidade, mas de nação.

A cidade - a cidade como questão - aparecia como uma cifra pela qual o país era tematizado e, em torno dela, organizava-se um jogo de referências que dava sentido às polêmicas, divergências, debates e embates sobre a história, percursos e destinações da sociedade brasileira. (TELLES, 2010, p. 63).

Com o assentamento da globalização, da financeirização da economia e da revolução tecnológica, os horizontes de uma modernidade pautada em uma cidadania ampliada se reduziram. Essa questão foi lançada em debate por Schwarz, que questiona, "como pensar o país se o aspecto da modernização que nos coube, assim como a outros, for o desmanche ora em curso, fora e dentro de nós?" (SCHWARZ, 1993, p.156).

Francisco de Oliveira, em seu ensaio "O Ornitorrinco", de 2003, também manifesta seu desencanto com a perspectiva de superação, noção fundante dos debates que percorreram as décadas anteriores, ao usar a imagem do animal para descrever o país: "um monstrengo feito de pedaços desconjuntados, diferenças, defasagens, descompassos, desigualdades, que, não sendo mais atravessados por uma virtualidade de futuro, não mais articulados internamente por uma 'dialética dos contrários', ficam onde estão, um neoatraso." (TELLES, 2010, p. 63).

Assim, com a transformação do modo de acumulação capitalista e a consequente reestruturação urbana, o espaço referencial sobre o qual se apoiavam os debates sobre a cidade - tanto o espaço urbano concreto, quanto o espaço de referências conceituais - se transformou fortemente, deixando ao campo dos estudos urbanos o desafio de projetar suas observações e análises sob novos parâmetros.

O que antes foi dito e escrito sobre a cidade e seus problemas, a "questão urbana", parece ter sido esvaziado de sua capacidade descritiva e potência crítica em um mundo que fez revirar de alto a baixo o solo social das questões então em debate (TELLES, 2010, p. 65). 
Naturalmente, os estudos urbanos do nosso tempo envolvem um campo de observação e análise diferente e mais complexo do que o cenário com base no qual os trabalhos pioneiros foram projetados. Os pilares de organização da vida social nas cidades foram reconfigurados com o passar dos anos, os universos familiar, do trabalho, da mobilização comunitária, da política, da sociabilidade e da violência se transformaram. Se, a partir dos anos 1960, se intensifica a formação de periferias urbanas como resultado, principalmente, do êxodo rural e da necessidade da expansão capitalista das cidades para absorver o crescente contingente de trabalhadores pauperizados, na atualidade as periferias já não se consolidam mais pela dinâmica da migração intensa, apesar de continuarem se constituindo como espaço possível de reprodução da população pobre e cumprindo a função de "fronteira de expansão para o capital", nos termos de Mautner (1999).

Quando os primeiros estudos sobre as periferias começaram a ser desenvolvidos, buscava-se produzir uma interpretação para um fenômeno de urbanização recém-inaugurado. Apreender os sentidos do movimento capitalista de produção das cidades figurava como uma meta inadiável aos que se esforçavam não apenas para compreender a conjuntura social e político-econômica, mas também projetar um modelo de desenvolvimento para o país. Não obstante essas pesquisas iniciais tratarem de um recorte espacial específico, qual seja, a periferização nas duas maiores metrópoles brasileiras, São Paulo e Rio de Janeiro, seus expoentes foram chamados a reconhecer as características próprias de cada localidade, informados sobre um suposto protagonismo de um viés teórico estruturalista e, até mesmo, normativo em seus trabalhos.

Telles (2010) reforça que a principal dificuldade que tem se colocado aos pesquisadores do urbano tem sido, exatamente, discernir sobre os acontecimentos do tempo presente e as linhas de força que os atravessam. A impetuosidade das transformações dissipa os esforços de trabalho sobre a experiência social do passado, ao mesmo tempo em que a imprevisibilidade e aleatoriedade dos fatos colocam os horizontes de possíveis dentro das circunstancias imperativas do mercado, de modo que o presente aparece capturado pelas urgências do momento e a gestão do cotidiano se configura como única prática disponível.

Parece que se perderam de vez as conexões que articulam o econômico, o urbano e o social: a economia é coisa que parece transitar definitivamente em outra galáxia de referências, a política passa a se reduzir ao problema da gestão das urgências de um presente imediato e o urbano parece se desconectar de vez com a política, para ser confinado às formas diversas, velhas e novas, de gestão da pobreza. (TELLES, 2010, p. 65-66).

Em um cenário em que o campo político se encontra limitado pelo presente imediato, sem abertura para outros possíveis, também o espaço da crítica se esvai. Esse deslocamento 
observado na esfera teórica da construção da cidade, muito pautado pela desarticulação do plano de referência anterior - que definia a direção das perguntas e entregava intensidade crítica e polêmica aos debates-, ocorre menos porque há um esvaziamento conceitual e mais pela necessidade pouco nutrida de se buscarem novos agenciamentos e polos de gravitação das questões (TELLES, 2010).

Cortado (2018) ressalta que nas últimas décadas os estudos urbanos se ampliaram dentro das ciências sociais; a categoria periferia, por exemplo, ganhou extensão considerável no campo da etnografia. O autor acredita que houve um "deslizamento semântico" na aplicação do termo dentro das ciências sociais, semelhante ao descrito por Durham (2004) em relação ao uso do conceito de ideologia. Esse efeito ocorreria devido ao modo equivocado com que os pesquisadores acionam os conceitos, principalmente os vinculados à tradição clássica da sociologia marxista, levando a um uso apartado de suas definições originais, das problemáticas históricas e políticas que os constituíram.

Os novos estudos urbanos apresentam a categoria periferia mais como característica do que como conceito. Na aproximação de seu uso com a noção de margem são construídas abordagens que buscam, exatamente, um afastamento de possibilidades analíticas com traços estruturalistas - marcado tanto por determinações políticas, quanto espaciais - e uma fluidez na utilização do termo. A complexidade desse campo de estudo que desponta reside em considerar que as margens não devem examinadas somente ou primordialmente por coordenadas espaciais, pois elas se expressam e se materializam em diferentes frentes, podendo ser políticas, religiosas, sociais, culturais etc., de modo que não criam nem constituem espaços fixos, homogêneos ou subordinados a um mesmo contexto.

Cortado (2018) pondera que essa busca por maior fluidez, ou transversalidade, para o termo periferia não surge, entretanto, acompanhada de alguma nova teoria. A categoria aparece sendo utilizada com base no caráter polissêmico da palavra "periferia", seja enquanto conceito analítico, seja como termo corriqueiro, que inclui os usos nativos. De modo que, se para os estudos clássicos periferia funcionava como um conceito dinâmico, indexado em um processo histórico, com ênfase na exploração do proletariado pelo modo de produção capitalista, nessa literatura atual a periferia serve como categoria tipológica. Por essa perspectiva, estudar periferia pode envolver um loteamento periférico, uma favela, um cortiço, um conjunto habitacional, um subúrbio, uma ocupação etc.

se a palavra "periferia" pode designar lugares tão diferentes quanto o "loteamento periférico", o cortiço da região central e o albergue para morador de rua, lugares onde, às vezes, nem os nativos se consideram como pertencendo à "periferia", por que ainda falar em "periferia" e não preferir o conceito de "margem", por exemplo? A manutenção da palavra, ao nosso ver, serve para aludir à problemática clássica da periferia, mas a referência aqui não vai muito além da alusão. (CORTADO, p. 69).

O esforço de refletir epistemologicamente, buscando expor o pensamento de diferentes pesquisadores e com publicações que contemplam distintos recortes temporais, parte de um interesse em identificar os avanços, rupturas e embargos que compõem a trajetória dos estudos urbanos no Brasil. Nessa caminhada, entre os autores que exprimem questões sobre o desenrolar da pesquisa urbana em ciências sociais, Kowarick se destaca, não apenas por sua produção que praticamente atravessa a construção da "cidade enquanto questão" no Brasil, mas por sua 
constância em apontar que o alinhamento com a realidade brasileira, com a conjuntura política, social e econômica, não pode deixar de compor a imaginação sociológica. Com o passar dos anos, o autor foi, também, cada vez mais, se aproximando de uma perspectiva de construção teórica que frisa a relevância da subjetividade social para a compreensão dos processos que correm nas cidades, entendendo que as questões que surgem no urbano se modificam no espaçotempo e se desdobram em variadas configurações sociais.

\section{Considerações finais: o legado de Kowarick como convite ao compromisso com a pesquisa urbana}

A leitura das obras de Kowarick nos permite acessar a ética de compromisso do autor com o modo e as condições de vida dos grupos da nossa sociedade cujo cotidiano é marcado pela vulnerabilidade em diferentes níveis. Essa intencionalidade é precisamente manifesta, por exemplo, em seu último texto publicado: "o que antecede as formulações teóricas nas minhas investigações são valores que norteiam os caminhos que precedem os rumos das elaborações de cunho analítico e interpretativo" (2020, p. 569). Kowarick faz indicações declaradas de que suas escolhas analíticas são também políticas e marcadas por princípios sólidos.

Tal desembaraço do autor em marcar posição em relação a um compromisso ético que precede o trabalho científico se realiza combinado com sua desenvoltura em revisitar as próprias construções analíticas, apontando inconsistências e reconhecendo, sem qualquer presunção, que suas contribuições são um processo "em movimento" (2020, p. 573). A exposição desse trabalho de retorno do pesquisador, tanto em relação aos construtos teóricos, quanto à sua trajetória de trabalho e vida, permite nos aproximarmos de seu processo de pensamento, sua metodologia e percursos de pesquisa.

A todo momento Kowarick nos convida a empreender com ele essa busca por uma construção analítica do urbano atenta aos processos econômicos e estruturantes e pautada na produção de experiências e suas mediações. Ressalta que a percepção das necessidades varia no tempo e no espaço e que, a despeito da institucionalização das legitimidades, "igualmente importante é a lenta, oscilante e contraditória dinâmica de desnaturalização do escanteamento presente no cotidiano de nossas metrópoles" (2020, p. 575).

Compreender que as necessidades e desejos que habitam o imaginário urbano não são estáticos, nem pré-determinados por algum tipo de normativismo urbano, figura como o primeiro passo necessário a ser dado pelo pesquisador. Convém, ainda, reconhecer o tempo e o espaço como agentes de práticas, visto que as estruturas espaciais - tais como infraestruturas e equipamentos urbanos, vias de acesso, empreendimentos imobiliários e comerciais etc. - se modificam temporalmente, insuflando e remodelando os conflitos que se materializam no terreno. É preciso, ainda, perseguir os caminhos e razões que levam as reivindicações a assumirem legitimidade, compreender os processos de transformação das negações em injustiças.

Para Kowarick, é para essa dinâmica que o pesquisador urbano precisa direcionar seu foco. As lutas urbanas não deveriam, segundo ele, ser analisadas com base em seu caráter pontual ou descontínuo, buscando uma compreensão imediata dos conflitos sociais e tendo por 
referência um padrão pré-determinado de eficiência. Seria preciso adaptar o olhar para o movimento constante de fluxo e refluxo, para as rupturas temporais e espaciais, para os impulsos de vigor reivindicatórios e os declínios de mobilização como partes que constituem o todo dos conflitos que se materializam nas cidades.

O empenho com a problemática urbana e a incansável preocupação em "enfrentar de modo teoricamente mais calibrado os vários aspectos das exclusões que desabam sobre os moradores e trabalhadores, bem como o processo de institucionalização dos direitos" (2020, p. 575) são, sem dúvidas, as principais contribuições de Kowarick para os estudiosos do urbano. Para além de sua inquestionável relevância no campo científico, ficam seu entusiasmo e seu compromisso com a construção coletiva de uma "questão urbana" genuinamente brasileira.

\section{Referências bibliográficas}

BONDUKI, Nabil; ROLNIK, Raquel. "Periferia da Grande São Paulo: reprodução do espaço como expediente da reprodução da força de trabalho". In: MARICATO, Ermínia (Org.). A produção capitalista da casa (e da cidade) no Brasil industrial. São Paulo: Alfa-Omega, 1979. p. 117-54.

CORTADO, Thomas J. À beira da cidade: política e poética da urbanização no Jardim Maravilha, "loteamento proletário" da Zona Oeste carioca.2018. Tese (Doutoramento no Programa de PósGraduação em Antropologia Social) - Universidade Federal do Rio de Janeiro, Rio de Janeiro, 2018.

HONNETH, Axel. Luta por reconhecimento: a gramática moral dos conflitos sociais. São Paulo: Editora 34, 2014.

KOWARICK, Lúcio. A espoliação urbana. Rio de Janeiro, Paz e Terra. (Coleção Estudos Brasileiros, 44.) 1979.

KOWARICK, Lúcio; CARVALHOSA, Margarida; GRAEFF, Eduardo. "Os cidadãos da marginal". In: KOWARICK, Lucio. A espoliação urbana. Rio de Janeiro: Paz e Terra, 1979.

KOWARICK, Lúcio. Escritos Urbanos. São Paulo: Editora 34, 2000.

KOWARICK, Lúcio Viver em risco: sobre a vulnerabilidade socioeconômica e civil. São Paulo: Editora 34, 2009.

KOWARICK, Lúcio. Sobre a construção de um instrumento de análise: A espoliação urbana. Novos Estudos. CEBRAP. São Paulo. v. 39, nº 03, 567-576, set./dez. 2020.

LEEDS, Anthony; LEEDS, Elizabeth (Orgs.). A sociologia do Brasil urbano. Rio de Janeiro: Zahar. 1978.

MARICATO, Ermínia (Org.). A produção capitalista da casa (e da cidade) no Brasil industrial. $2^{a}$.ed. São Paulo: Atlas, 1982. (Coleção Urbanismo)..

OLIVEIRA, Francisco de. Crítica à Razão dualista - O ornitorrinco. São Paulo: Boitempo, 2003.

PEREIRA, Vivian P. Conflitos urbanos e estratégias cotidianas de resistência: o processo de formação de um bairro periférico. 2015. 114 f. Dissertação (Mestrado em Planejamento Urbano 
e Regional) - Instituto de Pesquisa e Planejamento Urbano e Regional, Universidade Federal do Rio de Janeiro, Rio de Janeiro, 2015.

PERLMAN, Janice E. O mito da marginalidade: favelas e política no Rio de Janeiro. Rio de Janeiro: Paz e Terra. 1977.

SILVA, Luís A. Machado da. Mercados metropolitanos de trabalho manual e marginalidade. Dissertação de mestrado em antropologia social. Rio de Janeiro: Universidade Federal do Rio de Janeiro, MN. 1971.

TELLES, Vera da Silva. A cidade nas fronteiras do legal e ilegal. Belo Horizonte: Fino Traço, 2010.

THOMPSON, Edward P. Tradición, revuelta y conciencia de clase: estudios sobre la crisis de la sociedad preindustrial. Barcelona: Crítica, 1977.

VALLADARES, Lícia do Prado; FREIRE-MEDEIROS, Bianca. Olhares sociológicos sobre o Brasil urbano: uma visão a partir do UrbanData-Brasil. In: OLIVEIRA, Lúcia Lippi (Org.). Cidade: história e desafios. Rio de Janeiro: Fundação Getúlio Vargas, 2002. p.60-83. 